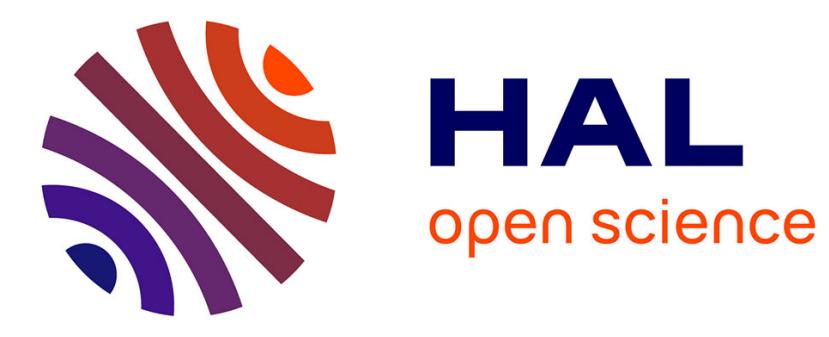

\title{
Fast, Frugal Image Reconstruction with a Dual Disperser Hyperspectral Imager
}

Elizabeth Hemsley, Ibrahim Ardi, Simon Lacroix, Hervé Carfantan, Antoine Monmayrant

\section{- To cite this version:}

Elizabeth Hemsley, Ibrahim Ardi, Simon Lacroix, Hervé Carfantan, Antoine Monmayrant. Fast, Frugal Image Reconstruction with a Dual Disperser Hyperspectral Imager. 2021 Conference on Lasers and Electro-Optics Europe \& European Quantum Electronics Conference (CLEO/Europe-EQEC), Jun 2021, Munich, Germany. pp.1-1, 10.1109/CLEO/Europe-EQEC52157.2021.9542719 hal-03407756

\section{HAL Id: hal-03407756 \\ https://hal.laas.fr/hal-03407756}

Submitted on 28 Oct 2021

HAL is a multi-disciplinary open access archive for the deposit and dissemination of scientific research documents, whether they are published or not. The documents may come from teaching and research institutions in France or abroad, or from public or private research centers.
L'archive ouverte pluridisciplinaire HAL, est destinée au dépôt et à la diffusion de documents scientifiques de niveau recherche, publiés ou non, émanant des établissements d'enseignement et de recherche français ou étrangers, des laboratoires publics ou privés. 


\title{
Fast, Frugal Image Reconstruction with a Dual Disperser Hyperspectral Imager.
}

\author{
Elizabeth Hemsley $^{1}$, Ibrahim Ardi ${ }^{1,2}$, Simon Lacroix ${ }^{1}$, Hervé Carfantan ${ }^{2}$, Antoine Monmayrant ${ }^{1}$ \\ 1. LAAS-CNRS, Université de Toulouse, CNRS, 7 Avenue du Colonel Roche, 31400 Toulouse, France \\ 2. IRAP, Université de Toulouse, CNRS, CNES, 14 Avenue Édouard Belin, 31400 Toulouse, France
}

Recently we demonstrated the reconstruction of a hyperspectral datacube with 110 wavelength bands from 10 camera acquisitions [1]. The implementation of this scheme, similarly to compressed sensing, relies on spatialspectral correlations within the scene. A digital micro-mirror device (DMD) provides programmable spatialspectral filtering, and is optimized to improve both the speed and accuracy of the reconstruction. Contrary to widespread approaches based on compressed sensing with a single disperser, our dual disperser architecture, illustrated in Figure 1a, allows straightforward access the panchromatic image and simpler reconstruction algorithms. In particular, we harnessed the panchromatic image to develop a simple edge-preserving quadratic regularization, which is faster than $\ell_{1}$ regularization and does not assume any sparse basis.

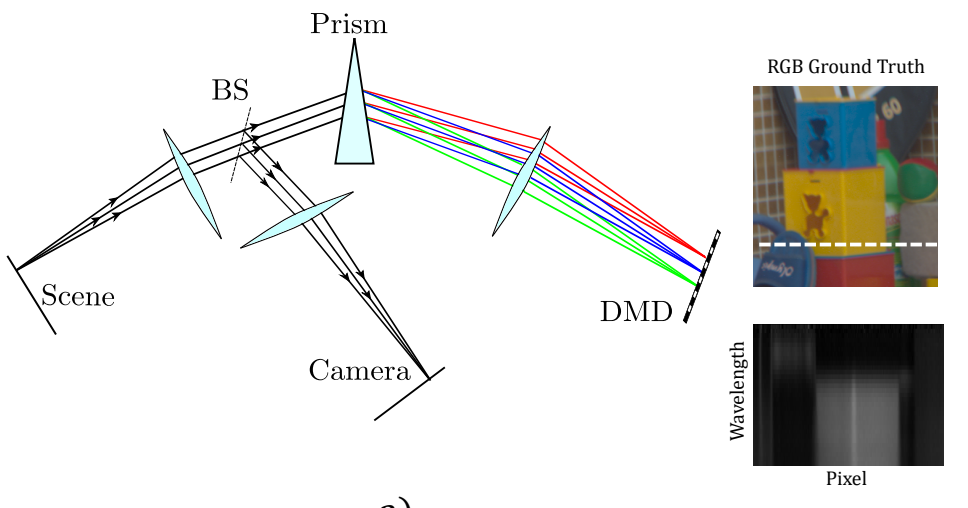

a)

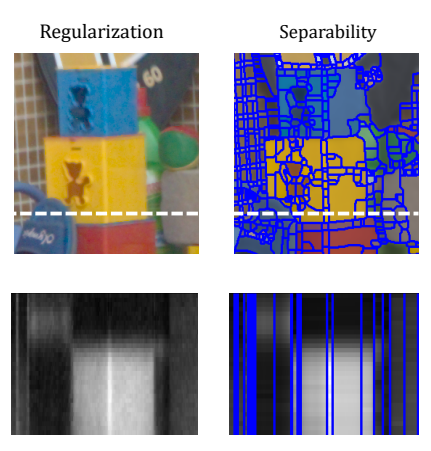

b)

Fig. 1 a) Schematic of dual disperser hyperspectral imager, b) Top row - comparison of ground truth to reconstruction via

regularization and segmentation, using simulated data. Bottom row - comparison of spectra for a line of pixels through the image.

The small number of camera acquisitions required for regularization allows a fast acquisition frame rate, but edge-preserving quadratic regularization is still too slow to ensure real-time hyperspectral cube reconstruction. Here we propose a novel approach that further increases the speed of reconstruction by relying on a separability assumption. Whilst regularization assumes that the scene has a smoothly varying spectra, except at edges visible on the panchromatic, our new approach assumes the scene can be divided into regions of homogenous spectra, initialized via segmentation of the panchromatic image, as illustrated in Figure 1b. This assumption allows almost instantaneous reconstruction of the scene from a smaller number of acquisitions [2], the resulting datacube is compressed, as pixels in each segment are assigned the same spectra, modulated by intensity.

For many applications the spectra of each individual pixel is not important, instead the classification of regions is of interest, and the approach presented here provides a method to obtain this result quickly using a minimum amount of data. As hyperspectral imaging applications are wide ranging, the data acquisition and reconstruction methods need to be similarly varied, reflecting the speed and accuracy requirements desired for differing applications. The method proposed here fills the gap between full-cube reconstruction schemes, which typically have a low frame rate and generate a lot of data, and compressive or deep-learning reconstruction, which are frugal but can be slow or require training. We intend to validate this method both theoretically and using experimental data, and at the conference we will present in detail both regularization and separability approaches, including our most recent experimental results.

\section{References}

[1] Elizabeth Hemsley, Ibrahim Ardi, Simon Lacroix, Hervé Carfantan, and Antoine Monmayrant, "Optimized coded aperture for frugal hyperspectral image recovery using a dual-disperser system," J. Opt. Soc. Am. A 37, 1916-1926 (2020)

[2] Ibrahim Ardi, Reconstruction d'images pour un imageur hyperspectral configurable, Université de Toulouse (2020) 